\title{
Environmental life cycle assessments for water treatment processes - A South African case study of an urban water cycle
}

\author{
E Friedrich", S Pillay ${ }^{2}$ and CA Buckley ${ }^{2}$ \\ ${ }^{1}$ Centre for Research in Environmental Coastal and Hydrological Engineering (CRECHE), School of Civil Engineering, \\ Surveying and Construction, University of KwaZulu-Natal, Durban 4041, South Africa \\ ${ }^{2}$ Pollution Research Group, University of KwaZulu-Natal, Durban 4041, South Africa
}

\begin{abstract}
The objective of this study was to generate information on the environmental profile of the life cycle of water, including treatment, distribution and collection and disposal (including recycling), in an urban context. As a case study the eThekwini Municipality (with its main city Durban) in South Africa was used. Another aim of the study was to compare the environmental consequences for the provision of normal, virgin potable water vs. recycled water to industry in Durban. Therefore, a series of environmental life cycle assessments (LCAs) were performed and environmental scores were calculated for the processes involved in the treatment, recycling and disposal of water and wastewater. In order to enable the addition of these scores the same approach was adopted and the same methodology was used and a final environmental profile was produced.

This study shows that a system approach as well as a process approach is needed for the integral assessment of the environmental performance in the provision of water and wastewater services. From the LCAs of individual processes involved in the provision of water and wastewater in the eThekwini Municipality, it emerged that the process with the highest contribution is the activated sludge process - used in the treatment of wastewater. However, when considering the entire system and including the losses in the distribution network for potable water, the process with the highest contribution became the distribution itself. An improvement analysis was performed and is presented. It takes into account a series of possible interventions and their consequences. Most notably, one conclusion of this study is that recycling as currently undertaken in Durban, has positive environmental impacts.
\end{abstract}

Keywords: urban water systems, recycling and reuse of water, water management, environmental impact

\section{Introduction}

The life cycle assessment (LCA) is a versatile environmental tool which can be tailored for different uses in the water industry. These range from very specific studies (e.g. the choice of different materials and/or chemicals) to process level applications and to strategic and regional applications. A detailed review of all applications of LCAs in the water industry is presented in Friedrich et al. (2007) and includes LCAs for water supply processes, for wastewater treatment plants, for sludge disposal, and for membrane filtration processes for the provision of the different materials needed for the infrastructure. From this review it is evident that the majority of local and international studies (Emmerson et al. (1995), Meijers et al. (1998), Dennison et al. (1998), Brydle and Skrypski-Mantele (2000), Hwang and Hanaki (2000), Zhang and Wilson (2000), Vidal et al. (2000), Raluy et al. (2005), Stokes and Horvath (2006) and Landu and Brent (2006)) take a process/project approach, were an LCA is used to investigate and/or compare individual water treatment processes or plants. Only a few studies (Lundie and Peters (2000), Tarantini and Ferri (2001) and Rihon et al. (2002)) are taking a more strategic approach which includes a whole water system in which different processes and plants are combined. None of these strategic/regional studies were conducted in the

\footnotetext{
* To whom all correspondence should be addressed.

잉 +2731 2607709 ; fax: +2731 2601411 ; e-mail: Friedriche@ukzn.ac.za

Received 29 February 2008; accepted in revised form 13 November 2008.
}

South African context. Therefore, this paper aims to address this gap and show how the LCA methodology was employed to investigate and improve a local water system, namely that of the eThekwini Municipality.

The eThekwini Municipality (South Africa) has a population of approximately 3.1 million and covers an area of about 2300 $\mathrm{km}^{2}$ (IDP, 2005). The core city of the municipality is Durban, which is the largest South African port city on the Indian Ocean. Inland it is surrounded by other urban nodes as well as other more sparsely populated peri-urban areas. Bulk potable water is provided to the municipality by Umgeni Water which operates two interdependent systems that are linked operationally and in terms of service delivery. Each system has a dedicated dam, aqueducts and a waterworks. The $1^{\text {st }}$ system is the Nagle Dam and the Durban Heights Waterworks and the $2^{\text {nd }}$ system is the Inanda Dam and the Wiggins Waterworks, as shown in Fig 1.

Once treated, the potable water is reticulated to consumers (domestic and industrial). In the central area and in the suburbs of the municipality, a sewer system collects the used water, which is treated in a number of sewage treatment plants prior to final discharge into the Indian Ocean. A water recycling plant, commissioned in 2001, takes treated sewage from the Southern Wastewater Treatment Plant to produce industrial-grade water, which is used in a paper mill and in an oil refinery. The main components of the system and their geographical location are presented in Fig. 1 and Fig. 2.

The overall objective of this study was to generate a holistic picture of the environmental life cycle of water in an urban setting and it includes the treatment, distribution, collection and disposal (including recycling) of potable water and wastewater. 


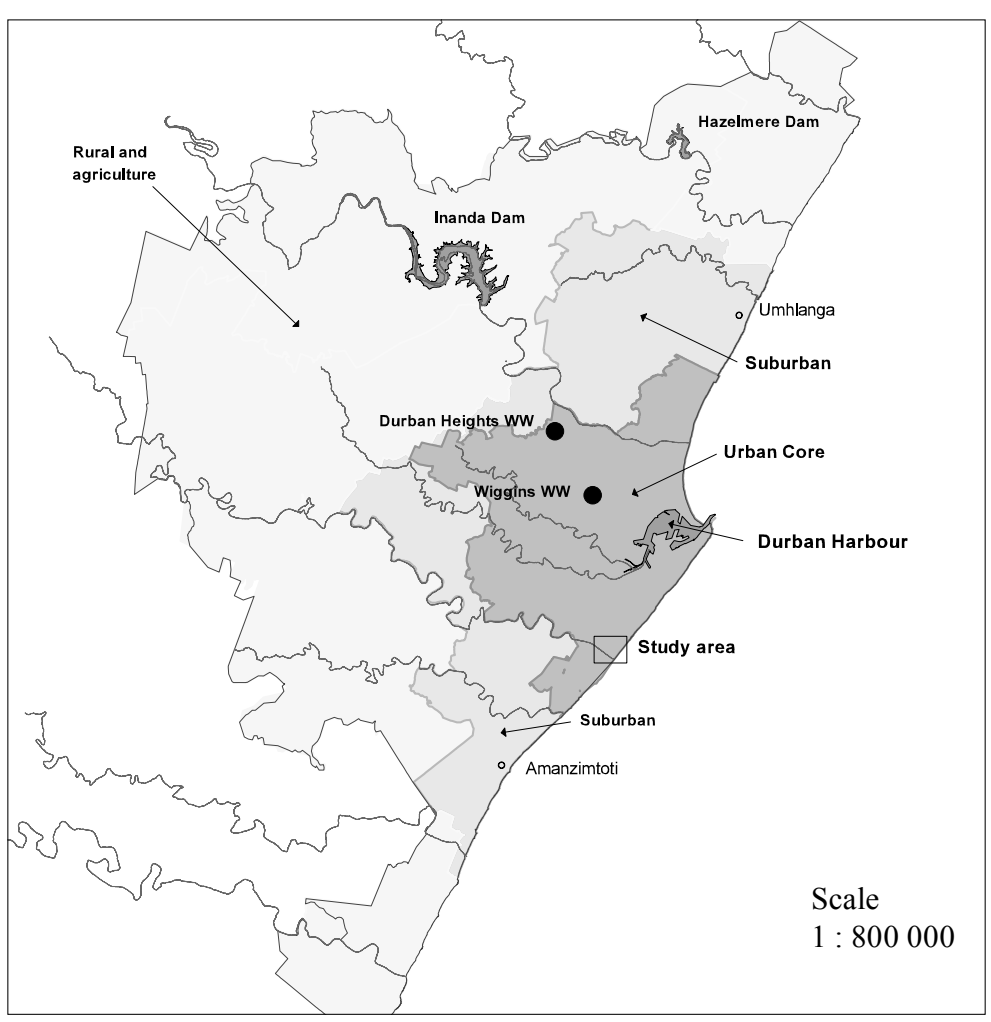

Figure 1

Location of dams, waterworks and study area within the eThekwini Municipality (Source: GIS Unit - eThekwini Municipality)

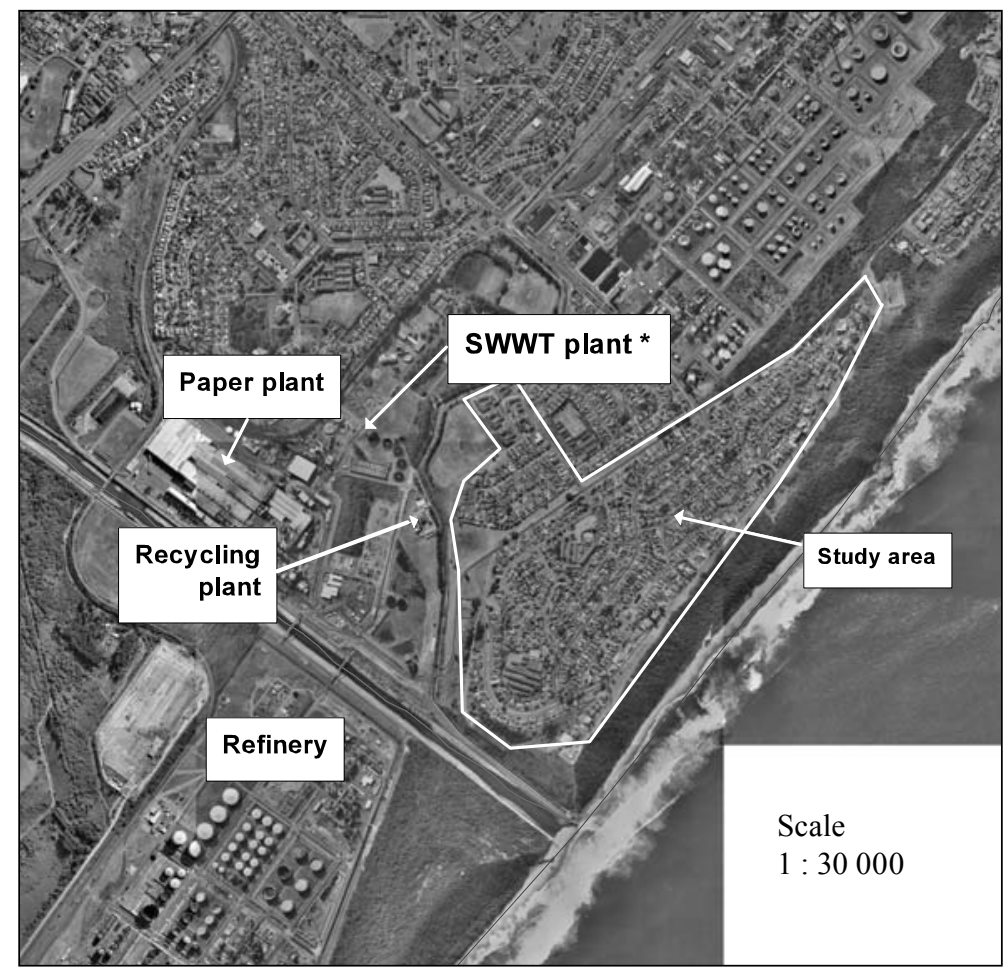

Figure 2

Aerial picture of the study area, the Southern Wastewater Treatment (SWWT) plant, the recycling plant and the industrial customers (Source: GIS Unit eThekwini Municipality)
This should be seen in the context of water scarcity in the country in general, and in particular in the Mgeni catchment in which the municipality is situated. Assessments and models (DWAF, 2004 and DWAF, 2007) indicate that it is fast becoming a water-stressed catchment, with demand exceeding supply, and thus the need for a reconciliation strategy with augmentation and/or water recycling as main options.

\section{Study approach}

The study on the treatment of potable water examined the inputs and outputs from the 2 water treatment plants (Wiggins and Durban Heights Waterworks - Umgeni Water) in the Durban area. The different inputs and processes for these 2 plants were quantified and environmental scores were calculated for each impact category. The distribution of potable water was studied for one particular distribution network, namely from Wiggins Waterworks to the southern Durban industrial area. This is the network, which includes the consumers (a paper mill and an oil refinery) in the vicinity of the water recycling plant. The geographical location of the dam, the waterworks (two for potable water and one for wastewater treatment), the area used to gather data for distribution and collection networks, as well as the recycling plant and the industrial consumers are presented in Fig. 1 and Fig. 2. The sewage collection system in the southern Durban industrial area (covering the same area as the potable water distribution system) was investigated in a similar manner as the distribution. The piping networks as well as the energy inputs due to pumping have been included. The treatment of wastewater and the recycling of water were investigated by using as case studies the Southern Wastewater Treatment Plant and the Durban Water Recycling Plant respectively. The treatment of wastewater includes primary treatment (de-gritting and primary settling) and secondary treatment (activated sludge and clarifiers). The recycling plant (also referred to as the tertiary treatment of wastewater) employed the following process units: lamellae settlers, dual media filters, ozonators, granular activated carbon filters and chlorinators. The chemicals used in tertiary treatment were also included. Environmental scores were calculated for these 5 sub-systems based on these inputs and outputs. In calculating these scores the CML methodology (Guinee et al., 2001) was used as implemented in the GaBi 3 environmental LCA tool.

\section{Methodology}

Life cycle assessments (LCAs) are environmental studies used to assess products, activities and processes by:

- Compiling an inventory of relevant inputs and outputs of a system

- Evaluating the potential impacts associated with those inputs and outputs 
- Interpreting the results of the inventory analysis and impact assessment phases in relation to the objectives of the study.

LCA studies the environmental aspects and potential impacts throughout a product's life (i.e. cradle-to-grave) from raw material acquisition through production, use and disposal. The general categories of environmental impacts needing consideration include resource use, human health and ecological consequences (ISO 2006).

For each of the components of the urban water cycle presented in the previous section, LCA studies have been conducted according to ISO 14040 standards and the steps set in the standards have been followed. These steps are: goal and scope definition, inventory analysis, impact assessment and interpretation. The general LCA methodology associated with the performance of these steps is presented in the relevant literature (ISO 14040, 2006 and Guinee et al., 2001). This section follows these main steps and includes the particulars and details pertinent to this case study.

\section{Goal and scope definition}

The overall goal of the study has been defined as being the provision of information on the environmental burdens of an anthropogenic water path in an urban context in South Africa. This included the determination of the environmental impacts (as expressed by LCA scores) in the treatment, distribution, collection, recycling and disposal of water and wastewater, as well as a comparison for the provision of water to industry (virgin vs. recycled water).

The functional unit was taken as $1 \mathrm{k} \ell$ of water at the quality specified for that particular process. For example for the production of potable water the functional unit is $1 \mathrm{k} \ell$ treated water to the quality specified by Umgeni Water and the eThekwini
Municipality as necessary for potable water. When combining the individual processes (treatment of raw water, distribution, collection and treatment of wastewater) into a system the water losses of these processes were taken into account.

Temporal variation of the quality of water, especially raw water has been observed (e.g. storm events, impoundment temperature-related turnover). These variations affect the inputs needed to produce the quality defined for the functional unit $(1 \mathrm{k} \ell)$. However, by using data from a 3 -year period (2004, 2005 and 2006) these temporal variations have been taken into account.

Figure 3 presents the boundaries of the system, showing the processes which have been included as well as the processes which have been left out.

Since such an extended system was studied, a series of assumptions had to be made with regard to the boundaries of this system. In this paper the environmental burdens due to the abstraction of water (i.e. the construction, operation and decommissioning of the dams) are not included. In the treatment processes of water/wastewater minor inputs (less than $0.5 \%$ contribution based on quantities) have been excluded after checking for toxicity, e.g. the nozzles used for filtration were excluded. . In the distribution and collection of water/wastewater the most important limitation is due to the lack of data for the pipes used in the entire municipality. To overcome this problem data were collected, but only for a study area containing 1828 households using $1.6 \mathrm{M} \ell / \mathrm{d}(1615 \mathrm{k \ell} / \mathrm{d})$ of potable water of the $820 \mathrm{M} \ell / \mathrm{d}$. This area might not be representative of the entire municipality; however, sensitivity analyses have shown that the results were not sensitive to great changes with regard to piping and pump material inputs and therefore, this limitation was considered acceptable. Stormwater was excluded from the inputs into the wastewater treatment works, although some of it enters indirectly. This was done by comparing data for the dry months

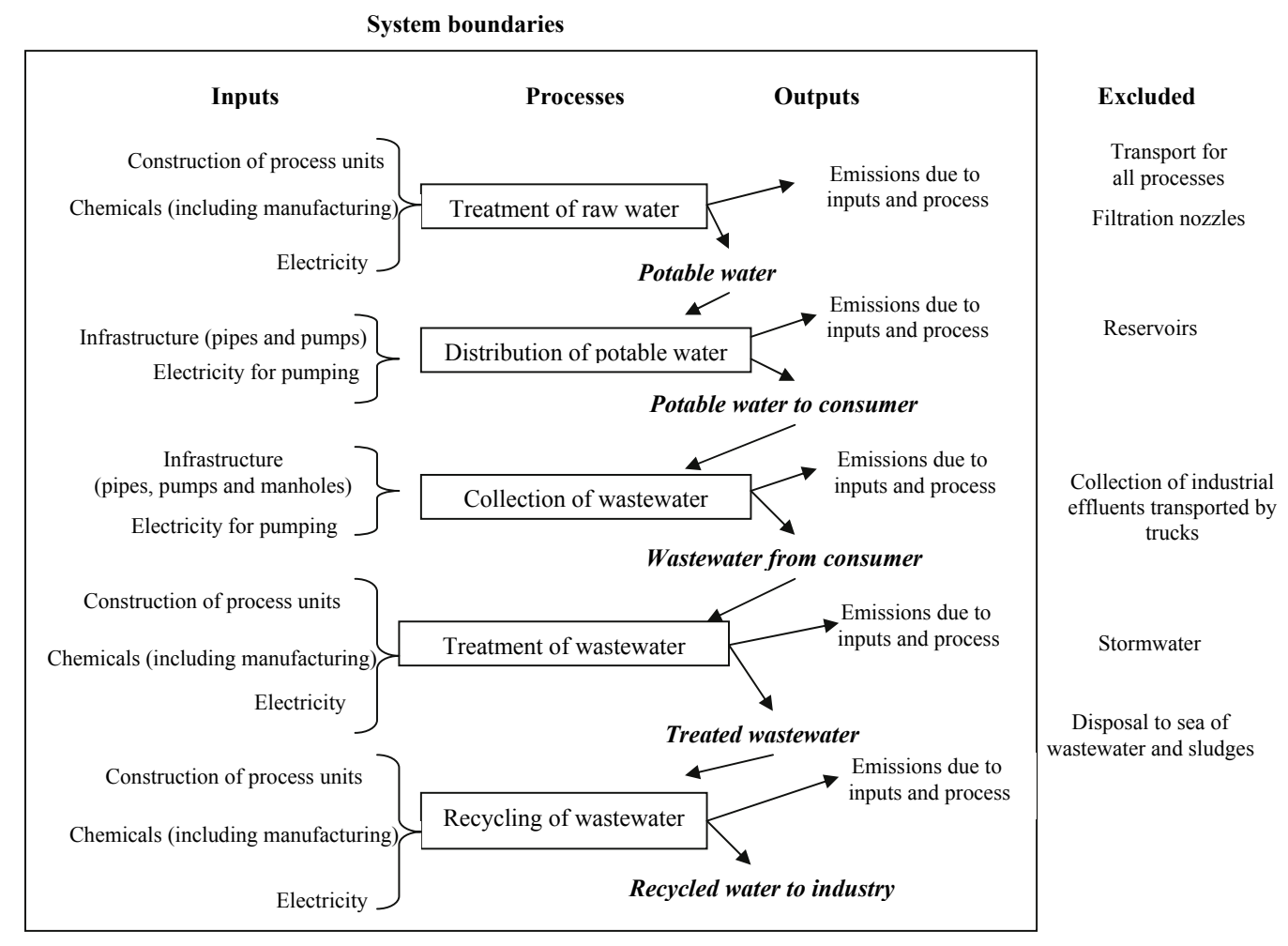

Figure 3

The boundaries of the system 
(June and July with no rain) with data from the rest of the year. As presented, the limitations due to the boundaries of the system have been noted; however, they have been accepted as sensitivity analyses have shown that the results (i.e. the environmental scores calculated) were not sensitive (less than $8 \%$ change for all scores) to changes in these inputs. The toxicity due to the disposal to sea of the wastewater which is not recycled, as well as of all the sludges resulting from the wastewater treatment processes (including recycling) has been investigated by means of bioassays (Friedrich et al., 2006).

\section{Data collection and inventory analysis}

The inventory and impact assessment calculations and the modelling of the system were performed by using the GaBi 3 software. Data were collected from various sources. For all the water treatment plants (potable water, wastewater and recycled water) direct data were collected with regard to the chemicals and energy used in the treatment of water (see Fig. 3). This was done with the direct assistance of the technical personnel from the waterworks and the municipality water services. Water data for the production of potable water were collected and environmental scores were calculated for both waterworks (Durban Heights and Wiggins Waterworks). From these, a final flow-weighted score was calculated for the supply of $1 \mathrm{k} \ell$ potable water in the entire eThekwini Municipality. The energy used for the distribution of potable water was obtained by totalling the energy used by all of the 107 pumping stations operated by the municipality plus the energy used by the Umgeni Water pumping stations. The water loss (30\%) in the distribution network was also taken into account. Similar calculations were undertaken for the collection of wastewater and the energy figures calculated are representative for the entire wastewater collection network for the eThekwini Municipality. Municipality-wide calculations for the materials used (i.e. pipes and pumps) were not possible due to the lack of an accurate and complete inventory of all the pipes in the system. Such an inventory would be very data intensive and could not be realistically obtained. Therefore, the geographical scale for the collection of data for piping (for potable and wastewater) had to be reduced to a case study area, which may not be representative for the entire municipality. This limitation was noted.

In an earlier LCA study (Friedrich, 2001) showed that the environmental impact of the capital goods, the structures and buildings on the waterworks, were of minor importance and therefore, efforts with regards to data collection have been concentrated on the processing inputs; however, these structures have not been ignored and are included. For the data on the chemicals used, the individual specific manufacturers were identified and data on the manufacturing processes were obtained. Where specific data were not obtainable, similar processes were included from LCA databases (mainly GaBi 3 ) or from the relevant scientific literature. Table 1 (next page) presents the processes included in the inventory and the source of the data used.

The authors acknowledge that by using a combination of data from various origins consistency issues may emerge (i.e. data might be collected at a different level of detail, different system boundaries and allocation rules might apply, etc.). To minimise this, the data collected directly as well as the data calculated were structured as closely as possible to the GaBi 3 format and the same level of detail was sought. Only one process (methanol production) was sourced from the TEAM 3 database. Another comment with regards to databases pertains to the geographical origins of the data; in the case of $\mathrm{GaBi} 3$ it is European data, and the fact that it might not be as representative for South Africa as it is for Europe. However, in the absence of South African data, European data had to be used and further investigations are necessary with regard to the impact of using imported data.

Data quality for the life cycle inventory is considered good. Data were collected and aggregated for a 3-year period (2004, 2005 and 2006) and the implementation of improvements (as presented in the improvement analysis) has been started during the study. The improvement process continues and this paper summarises the improvements over a 2-year (2006 and 2007) period. All direct input data are first hand-collected directly for individual processes. This includes data on electricity use and these data have been collected directly making use of different direct measurements. With regard to the data on the inputs and outputs due to the production of direct inputs, LCA databases have been used extensively. In one instance (the production of a particular polycoagulant used for potable water treatment) calculations had to be employed for some of the chemicals used to manufacture the inputs into the production of the precursors used for the polycoagulant. Therefore, there are no data gaps; however, the quality of the data might vary (calculated data are not real data even if real-life yields and efficiency factors were used). However, in the entire system the mass of these inputs were considered small enough (e.g. $2.17 \mathrm{~g}$ coagulant per $\mathrm{k} \ell$ water) so that possible differences between calculated data and real data (which was unobtainable) would not impact the results. Sensitivity analyses were used to check the assumptions and found that the results (i.e. the scores in the environmental profile) were not sensitive to variations to chemical inputs. Allocation of environmental burdens (i.e. in processes which had more than one output but only one of these outputs were included in the current system) were avoided wherever possible. Whenever it was not possible a worst-case scenario was assumed, i.e. the whole burden was included in this study. This was the case for the manufacturing processes for some of the chemicals (e.g. polyamines used in the polycoagulant). Again, sensitivity analyses were used to check these assumptions and found that the results were not sensitive to variations to these inputs.

Using input and output data, an inventory was produced for all processes involved (treatment of raw water, distribution of potable water, collection of wastewater, treatment of wastewater and recycling). In producing these inventories the inputs were calculated per $1 \mathrm{k} \ell$ of water/wastewater at the quality specified for that particular process. In order to summarise these inventories and to highlight key areas the impact assessment was performed.

\section{Impact assessment}

The impact analysis assesses the significance of the potential impacts resulting from the inputs and outputs of the system as presented in the inventory. Each entry of the inventory is translated into contributions to environmental problems and human health. In the ISO 14040 standards (ISO, 2006) the following elements are considered mandatory for this phase: selection of impact categories, category indicators and characterisation models (also referred to as category definition); assignments of inventory results to the impact category (classification) and calculation of category indicator results (characterisation). Optional elements are normalisation (calculation of the magnitude of category indicators results relative to reference information), grouping, weighting and data quality analysis. All the scores from all the categories considered comprise the environmental profile of the system or product studied. For this study only the mandatory 


\begin{tabular}{|c|c|}
\hline \multicolumn{2}{|r|}{$\begin{array}{l}\text { TABLE } 1 \\
\text { Sources of data for the different processes included in the inventory }\end{array}$} \\
\hline Process & Sources of data and observations \\
\hline \multicolumn{2}{|l|}{ Treatment of raw water } \\
\hline$\overline{\text { Construction of process units }}$ & $\begin{array}{l}\text { Data were collected directly from the bill of materials for concrete structures (cement, sand, stone and water) } \\
\text { and measured (pipes and pumps). Cement data were collected locally; however, data on the manufacturing of } \\
\text { the materials used for pipes and pumps (PVC, steel, copper and aluminium) are of European origin (GaBi } 3 \\
\text { database). }\end{array}$ \\
\hline Production of chemicals & $\begin{array}{l}\text { Data were collected directly for locally manufactured chemicals (sodium hypochlorite (manufactured on site), } \\
\text { liquid oxygen, polycoagulant, activated carbon, bentonite and lime) For the manufacturing of the chemicals } \\
\text { blended in the polycoagulant calculations and European data (from Gabi 3) were used. For the production of chlo- } \\
\text { rine gas local data were used. Data on the production of methanol (which is used to produce one of the polyamides } \\
\text { which is part of the polycoagulant) was average global data (sourced from the TEAM } 3 \text { database). }\end{array}$ \\
\hline Electricity used & $\begin{array}{l}\text { Direct electricity consumption measurements were used. For the production of electricity, initially European, } \\
\text { closely matched data were used (i.e. the calorific value of the coal combusted as well as some of the chemical } \\
\text { characteristic were almost identical to the South African coal and the technology was similar). However, this was } \\
\text { improved with the release of local electricity data and the major difference was in the sulphur content of the coal, } \\
\text { having implications mainly for acidification. }\end{array}$ \\
\hline \multicolumn{2}{|l|}{ Distribution of potable water } \\
\hline Construction of infrastructure & $\begin{array}{l}\text { In the absence of general data, the infrastructure (pipes and pumps) of a defined area was inventoried (pipe } \\
\text { length, materials, diameter, thickness; pump capacity and make-up) and calculated per } 1 \mathrm{k} \ell \text { of water moved in } \\
\text { that area. This has been generalised for the entire municipality. Data for the manufacture of the materials used } \\
\text { for piping (asbestos cement, steel and PVC) were sourced locally for asbestos cement and European data (from } \\
\text { GaBi 3) were used for PVC and steel. }\end{array}$ \\
\hline Electricity for & $\begin{array}{l}\text { Direct electricity measurements from all the pumps used in the distribution of potable water in the entire munici- } \\
\text { pality were used. }\end{array}$ \\
\hline \multicolumn{2}{|l|}{ Collection of wastewater } \\
\hline Electricity for pumping & $\begin{array}{l}\text { In the absence of general data, the infrastructure (pipes, manholes and pumps) of a defined area was inventoried } \\
\text { (pipe length, materials, diameter, thickness; pump capacity and make-up; number of manholes and their struc- } \\
\text { ture) and calculated per } 1 \mathrm{k} \ell \text { of wastewater moved out of that area. This has been generalised for the entire munic- } \\
\text { ipality. Data for the manufacturing of the materials used for piping and manholes (asbestos cement, vitrified clay } \\
\text { and concrete) were sourced locally for asbestos cement and concrete and from literature for vitrified clay. } \\
\text { Direct electricity measurements from all the pumps used for wastewater in the entire municipality were used. }\end{array}$ \\
\hline \multicolumn{2}{|l|}{ Treatment of wastewater } \\
\hline$\overline{\text { Construction of process units }}$ & $\begin{array}{l}\text { Data were collected directly from the bill of materials for concrete structures (cement, sand, stone and water) } \\
\text { and measured (pipes and pumps). Cement data were collected locally; however, data on the manufacturing of } \\
\text { the materials used for pipes and pumps (PVC, steel, copper and aluminium) were of European origin (sourced } \\
\text { from GaBi3). } \\
\text { Direct electricity consumption measurements were used. }\end{array}$ \\
\hline \multicolumn{2}{|l|}{ Recycling of water } \\
\hline$\overline{\text { Construction of process units }}$ & $\begin{array}{l}\text { Data were collected directly from the bill of materials for concrete structures (cement, sand, stone and water) } \\
\text { and measured (pipes and pumps). Cement data was collected locally; however, data on the manufacturing of } \\
\text { the materials used for pipes and pumps (PVC, steel, copper and aluminium) were sourced from GaBi3 and are } \\
\text { European data. }\end{array}$ \\
\hline Production of chemicals used & $\begin{array}{l}\text { Data were collected directly for locally manufactured chemicals (polyaluminium chloride, ferric sulphate, liquid } \\
\text { oxygen, polycoagulant, and lime) For the manufacturing of the chemicals blended in the polycoagulant calcula- } \\
\text { tions and data from overseas (from Gabi 3) were used. For the production of chlorine gas local data were used. } \\
\text { Data on the production of methanol (which is used to produce one of the polyamides which is part of the polyco- } \\
\text { agulant) was average global data (sourced from the TEAM } 3 \text { database). }\end{array}$ \\
\hline Electricity for processes & \\
\hline
\end{tabular}

steps have been performed and the scores presented in the following section are the calculated scores at the end of the characterisation (category indicator results) stage. In performing these steps the CML methodology was used (Guinee et al., 2001).

The CML methodology has been developed at the Center for Environmenal Studies (CML), University of Leiden in The Netherlands. It is one of the most used LCA methodologies within the LCA scientific community and is based on current scientific principles, models and calculations. As such it defines a series of environmental impact categories and presents the methodology to calculate indicator results for each category included. These categories are: global warming, ozone depletion, acidification, eutrophication, photo-oxidant (or smog) formation, toxicity (aquatic ecotoxicity, terrestrial ecotoxicity and human toxicity), energy use, abiotic resource depletion, solid waste and land use (Guinee et al., 2001). In the South African context this meth- odology has a series of shortcomings, most notably it does not include water as a resource (water quality issues are included) and salinisation as an environmental impact since these impact categories have not been seen as relevant by the original developers in Europe, however, they are very relevant locally. Also the way land use is incorporated in this methodology might not be the most appropriate approach for South Africa since loss of biodiversity from land use change is not touched on. Therefore, by using the CML methodology these impacts which are very relevant for the South African context are not appropriately addressed. A methodology to address salinisation has been developed for local use (Leske and Buckley, 2004) but is not yet validated. The limitations of using the CML methodology have been noted.

For most of the inputs used (chemicals, infrastructure and other materials) the omission of water usage has limited impli- 


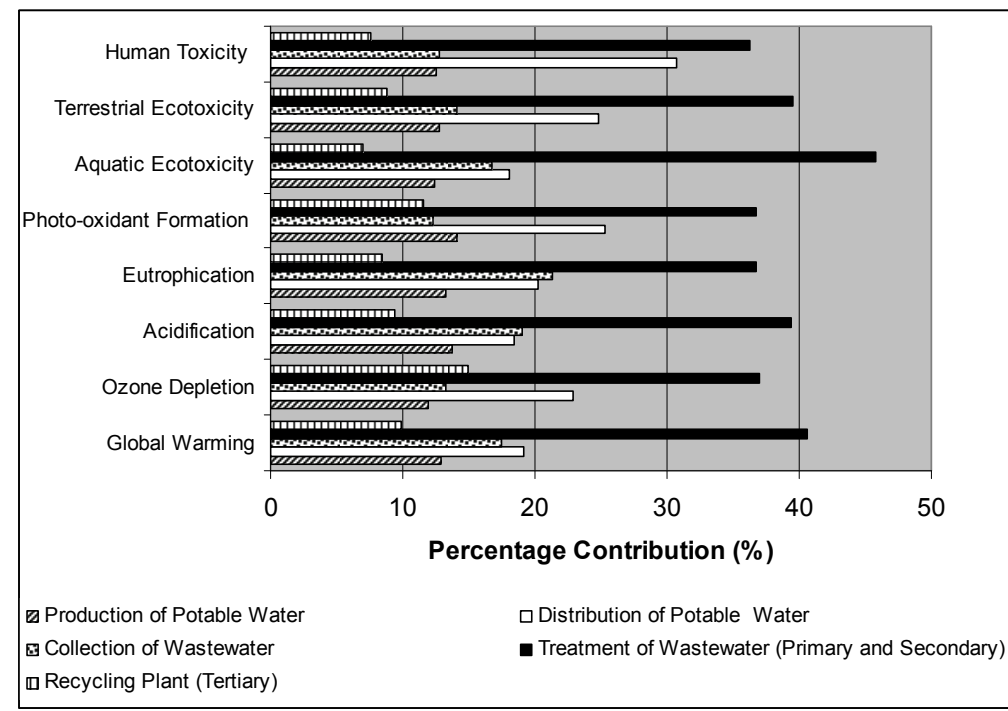

Figure 4

Contribution of individual processes to environmental impact categories process approach cations as the omissions pertain to the European data used (i.e. mainly for the production of chemicals but also for steel, copper and PVC). Per functional unit ( $1 \mathrm{k} \ell$ of water) these European inputs were considered small and sensitivity analyses have shown that the other impact categories linked to these inputs were not of importance. Because of the small quantities involved it is assumed that water consumption follows the same trend. Some of the speciality chemicals were imported and the water used for overseas manufacturing has no impact in South Africa. However, with regard to the water abstracted, treated, used (including recycling) and discharged (the functional unit itself) the implications are different and water has to be recognised as a valuable resource and losses should be minimised as much as possible. Therefore, the omission of this impact by the CML methodology has been compensated by highlighting the losses in the water system and by providing an improvement analysis, parts of which are already implemented. This improvement analysis debates these issues further.

The omission of other environmental impact categories like salinisation and loss of biodiversity from the CML methodology used introduces a limitation into this study. Further research is needed into validating salinisation as an impact category for South Africa and into developing an impact category to address the loss of biodiversity.

In this paper the CML default impacts categories were considered. These are: global warming, ozone depletion, acidification, eutrophication, photo-oxidant (or smog) formation and toxicity (aquatic ecotoxicity, terrestrial ecotoxicity and human toxicity). Scores for these categories have been calculated for $1 \mathrm{k} \ell$ of water (of different quality) for each of the processes researched (abstraction, treatment of raw water, distribution of potable water, collection of wastewater, treatment of wastewater and recycling of water).

In this paper the interpretation stage as required by the ISO 14040 methodology is presented in the Results and Discussion section.

\section{Results and discussion}

LCA scores were calculated for global warming, ozone depletion, acidification, eutrophication, photo-oxidant (or smog) formation and toxicity (aquatic ecotoxicity, terrestrial ecotoxicity and human toxicity). Some of the preliminary scores from this project have been published (Friedrich et al., 2006; Friedrich et al., 2007 and Pillay, 2007) in other contexts. However, the results presented in this section have been refined and the interpretation and improvement analysis extended and updated. The aim of the first section is to present the contribution of individual processes with the aim of identifying the processes with the highest contribution. In the next section the high-impact processes are targeted for an improvement analysis.

\section{The environmental impacts of the system}

The contribution of individual processes towards the environmental scores for the eThekwini system has been summarised in Fig. 4. This contribution has been calculated based only on the performance of the individual process (treatment of raw water, distribution of potable water, collection of wastewater and treatment of wastewater (including recycling)).

From the processes included in Fig. 4 it is evident that per kilolitre of water/wastewater the process with the highest scores for all environmental impacts is the treatment of wastewater. The $2^{\text {nd }}$ highest scores are carried by the distribution of potable water and the $3^{\text {rd }}$ highest scores are for the collection of wastewater. The lowest overall LCA scores (with the exception of the ozone depletion potential) are due to the recycling process. Therefore, in this case, it is more environmentally friendly to recycle wastewater and use it to replace virgin potable water. Not only is the recycling process more environmentally friendly than the treatment of raw water, but if one also considers potable water distribution and wastewater collection this difference in environmental performance is even more pronounced.

Therefore, supplying industries situated close to wastewater treatment plants with recycled water should be encouraged and promoted. This conclusion is also supported by another South African study (Landu and Brent, 2006), where the extraction of water from the environment is seen as the most important impact in the supply of water. Recycling of water will obviously reduce the need for extraction, treatment, distribution and collection. It will save a scarce resource and reduce the environmental burdens associated with the treatment and distribution of water.

In addition to the environmental performance of individual processes within an urban water system, the overall efficiency of the system has to be taken into account. There are different losses associated with the different processes. As an overview, Table 2 presents the amount of water which has to be 


\begin{tabular}{|l|c|c|}
\hline \multicolumn{3}{|c|}{ TABLE 2 } \\
\hline Process & $\begin{array}{c}\text { Amount } \\
\text { (ke) }\end{array}$ & $\begin{array}{c}\text { Loss } \\
(\%)\end{array}$ \\
\hline Abstraction of water - Inanda Dam & 1.47 & 0 \\
\hline Purification of water - Wiggins and Durban Heights Waterworks & 1.43 & $3 \%$ \\
\hline Distribution of water- municipality & 1.43 & $30 \%$ \\
\hline Water to domestic consumers & 1 & $40 \%$ \\
\hline Collection of wastewater from consumer & 0.60 & $0 \%$ \\
\hline Treatment of water & 0.60 & $0 \%$ \\
\hline
\end{tabular}

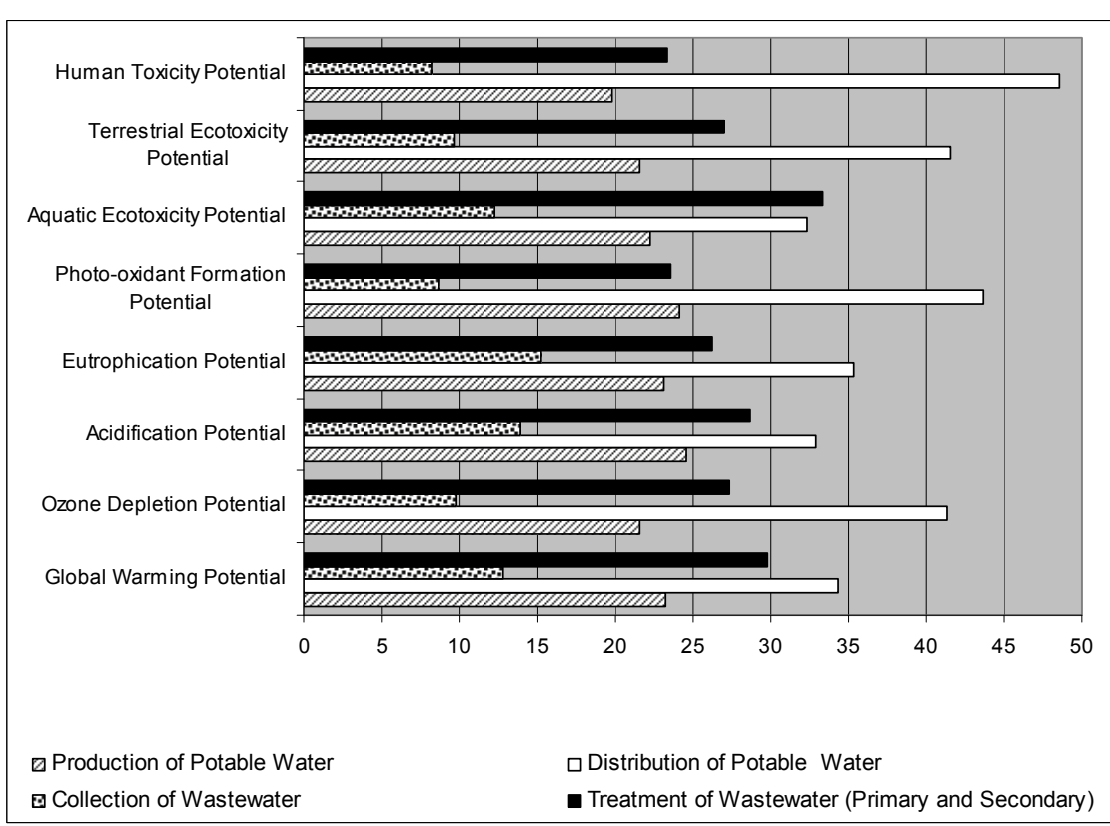

Figure 5

Contribution of individual processes to environmental impact categories - system approach

extracted and treated in order to supply $1 \mathrm{k} \ell$ of potable water to the consumers in the study area (see Fig. 2). To deliver this amount $(1 \mathrm{k} \ell)$ to consumers, $1.47 \mathrm{k} \ell$ need to be extracted from Inanda Dam and to be treated at Wiggins Waterworks. The water losses in the aqueduct linking Inanda Dam to Wiggins Waterworks are minimal and assumed to be zero. The losses at Wiggins Waterworks are about $1.5 \%$ and those from Durban Heights Waterworks are about 3\% (Thompson, 2006). For these calculations the worst-case scenario of $3 \%$ loss was considered. The loss in the distribution network of the eThekwini Municipality is about $30 \%$ (Scruton, 2007). At the consumer level, of the $1 \mathrm{k} \ell$ delivered only $0.6 \mathrm{k} \ell$ wastewater is collected ( $40 \%$ loss). It is assumed that the wastewater loss in the collection network, due to leakage is zero. The amount entering the wastewater treatment plant is $0.6 \mathrm{k} \ell$, and as the loss during treatment is assumed zero, $0.6 \mathrm{k} \ell$ enters the recycling plant and becomes available for industrial use. From these figures the overall loss from abstraction to recovered water is $59 \%$. In calculating these losses water recycling was not included. It must be underlined that these losses determine the amount available for recycling.

The environmental burdens associated with these losses vary. The burdens associated with the losses in the distribution network ( $30 \%$ loss) are considered high since the water lost has to be abstracted and treated. In other words, resources (chemicals and energy) are used to produce and pump water which is then lost. In addition to the environmental implications, there are also financial implications for the municipality since this water cannot be billed (also called non-revenue water). The burdens associated with the loss at consumer level ( $40 \%$ loss) are considered to be lower because this water is used and returned to the environment, not just inside the water provision cycle. For example, the losses at consumer level also include the water used for watering gardens and washing cars. The issues at this level are around promoting efficient use of water and they will be addressed in the improvement analysis.

Taking into account the losses presented in Table 3 and the environmental percentage contributions as shown in Fig. 3 new scores were calculated for $1 \mathrm{k} \ell$ of water delivered to the consumers. Figure 5 presents the environmental percentage contribution for each impact category recalculated on this basis.

By taking a system approach and including the water losses, the process with the highest environmental burdens becomes the distribution of potable water (see Fig. 5) and not the treatment of wastewater (primary and secondary) as shown by the contribution of individual processes (see Fig. 4). This illustrates the importance of adopting a system approach in assessing urban water systems and in prioritising improvements in order to achieve a more sustainable outcome for these systems. Environmental profiles and scores for individual processes are important but they do not present the complete picture since systemic water losses, which are typical for water systems, are not captured by investigating individual processes. However, a process approach is very useful in terms of the improvement analysis, since different organisations and/or entities are in charge of the different processes and can enact changes. It is the reason why for water systems, a process approach and a system approach should be adopted concurrently. 


\begin{tabular}{|l|c|c|c|}
\hline \multicolumn{3}{|c|}{ EABLE 3 } \\
\hline & $\begin{array}{c}\text { Environmental savings from replacing virgin water with recycled water } \\
\text { water (treatment and } \\
\text { distribution) }\end{array}$ & $\begin{array}{c}\text { Recycling of waste- } \\
\text { water }\end{array}$ & $\begin{array}{c}\text { Environmental } \\
\text { saving } \\
\%\end{array}$ \\
\hline $\begin{array}{l}\text { Impact category } \\
\text { (kg CO, equivalents) }\end{array}$ & $4.81 \mathrm{E}-01$ & $1.01 \mathrm{E}-01$ & $\mathbf{7 9}$ \\
\hline $\begin{array}{l}\text { Ozone depletion potential } \\
\text { (kg CFC-11 equivalents) }\end{array}$ & $1.10 \mathrm{E}-08$ & $3.19 \mathrm{E}-09$ & $\mathbf{6 8}$ \\
\hline $\begin{array}{l}\text { Acidification potential } \\
\text { (kg SO } \text { equivalents) }\end{array}$ & $2.85 \mathrm{E}-03$ & $5.68 \mathrm{E}-04$ & $\mathbf{8 3}$ \\
\hline $\begin{array}{l}\text { Eutrophication potential } \\
\text { (kg Phosphate equivalents) }\end{array}$ & $2.05 \mathrm{E}-04$ & $3.51 \mathrm{E}-05$ & $\mathbf{8 0}$ \\
\hline $\begin{array}{l}\text { Photo-oxidant formation potential } \\
\text { (kg ethene equivalents) }\end{array}$ & $5.28 \mathrm{E}-05$ & $1.05 \mathrm{E}-05$ & $\mathbf{8 4}$ \\
\hline $\begin{array}{l}\text { Aquatic ecotoxicity potential } \\
\text { (kg DCB* equivalents) }\end{array}$ & $6.45 \mathrm{E}-03$ & $1.00 \mathrm{E}-03$ & $\mathbf{8 4}$ \\
\hline $\begin{array}{l}\text { Terrestrial ecotoxicity potential } \\
\text { (kg DCB* equivalents) }\end{array}$ & $7.88 \mathrm{E}-01$ & $1.25 \mathrm{E}-01$ & $\mathbf{8 8}$ \\
\hline $\begin{array}{l}\text { Human toxicity potential } \\
\text { (kg DCB* equivalents) }\end{array}$ & $1.49 \mathrm{E}-02$ & $1.77 \mathrm{E}-03$ & \\
\hline & & & \\
\hline
\end{tabular}

*All toxicity scores are expressed in $\mathrm{kg} D C B(1,4$ dichlorobenzene) equivalents

\section{Impacts of water recycling}

When taking into account the losses in the system and the associated environmental scores due to these losses, the recycling of water becomes even more attractive. Table 3 presents the environmental savings for each LCA impact category due to the replacement of $1 \mathrm{k} \ell$ of virgin water with $1 \mathrm{k} \ell$ of recycled water at consumer level. For virgin water the scores for the treatment and distribution processes were added.

From Table 3 it is evident that in the case of the water recycling plant in the eThekwini Municipality the environmental savings due to the replacement of virgin water with recycled water are substantial for all environmental impact categories considered. When investigating the efficiency of recycling water in general and in this particular case study, it must be mentioned that according to the South African Water Act (Act 36 of 1998) and the resulting regulations, the wastewater has to be treated before being released into the environment to certain standards. The quality of the discharged water is very close to the demands of industry and in many cases needs little improvement. Therefore, the wastewater discharge quality requirements may act as a driver to recycling, especially in inland locations.

\section{Improvement analysis}

When 'drilling down' through the LCA results as presented in Fig. 4, the contributor, which carries the highest environmental burdens, is the use of electricity, which in South Africa is generated mainly by using coal (ESKOM , 2006). It dominates the scores for all the environmental impact categories as presented in Fig. 4 and Fig. 5. The relative proportions of electricity and chemicals to the different impact categories of the system are presented in Fig. 6. More details on individual stages are presented in a technical report (Friedrich et al., 2006). This is an argument for the use of an electricity index as a measure of environmental performance for urban water systems in South Africa (Friedrich et al., 2007).

Comparing the results from this case study with the results from similar international studies, energy consumption in water

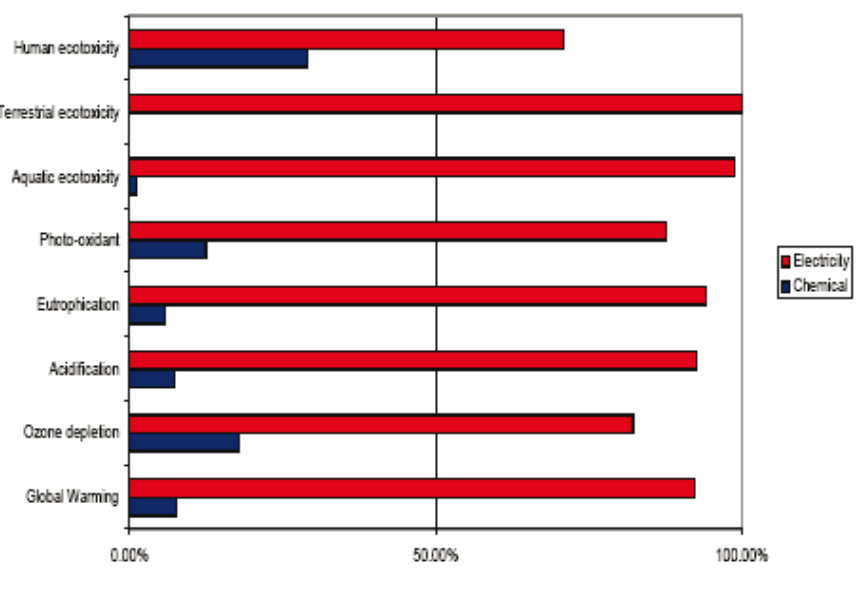

Figure 6

Contribution of electricity and chemicals to the environmental scores of the system

systems is a common theme. In a study for the city of Bologna (Tarantini and Ferri, 2001) the production and distribution of drinking water, the collection of used water, its treatment and disposal were researched. A year later Rihon et al. (2002) published the LCA results for the hydrographic basin of La Vesdre, Belgium. Detailed comparison of these 2 studies and with the South African study is not possible because of the different methodologies and approaches followed. However, they reach the same main conclusion, namely, that energy consumption in water systems is the most important factor, causing high proportions of the environmental burdens attributed to these systems. Although energy (i.e. electricity) is produced differently in Europe (the 2 case studies were from Italy and Belgium) and South Africa, the conclusions are similar, underlining the overall importance of energy in the environmental performance of water systems Because energy in water systems is considered so important, a more recent study from California (Stokes and Horvath, 2006) focused only on this aspect in a life cycle energy assessment which investigated 3 alternatives for supplying potable water for northern and southern California. What emerges 


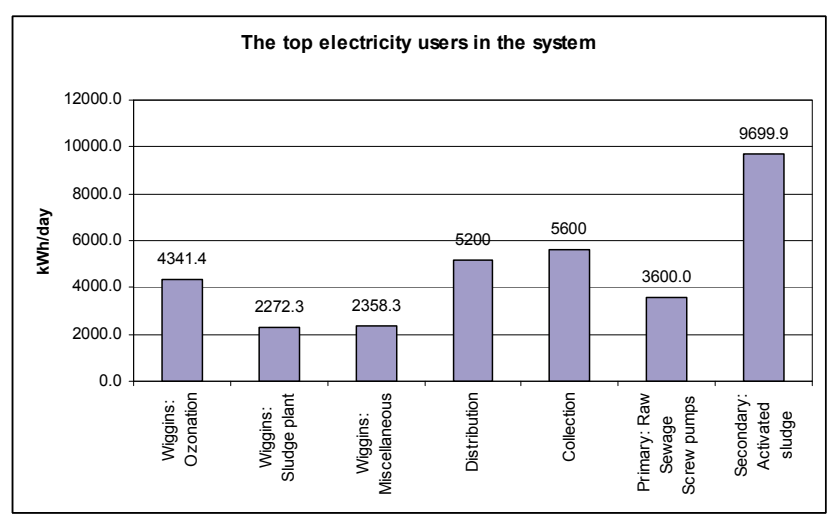

Figure 7

Graph of the top electricity-intensive processes for the operations phase of the system

from these LCA studies (international and the eThekwini one) is that the analyses of the energy requirements of each system are highly dependent on local conditions and cannot be generalised.

A process which is efficient in one system may be very inefficient in another system and factors like distances, needs for pumping, use of free gravity, etc. interplay to give a specific energy requirement for each system. Therefore, a case-by-case approach for energy consumption is needed. This is particularly relevant for the recycling of water, because the environmental gains from replacing virgin potable water with recycled water can be offset by the energy requirements to pump the recycled water to customers (i.e. long distances or to a high elevation). For example, the recycling operation in the eThekwini Municipality might become environmentally inefficient if new customers were located further away and the recycled water has to be pumped over larger distances. Currently the break-even point with regard to environmental burdens based only on energy consumption is calculated to be an equivalent pressure head of $200 \mathrm{~m}$.

Figure 7 presents the electricity-intensive processes within the entire system. The highest specific consumption of electricity within the system is from the ozonation units used in the production of potable water, the pumping of potable and wastewater in the distribution and collection networks and the activated sludge process in the treatment of wastewater. These are the units which have been targeted for a detailed improvement analysis. When considering the treatment of raw water Wiggins Waterworks has been targeted, as it has the highest electricity consumption per kilolitre of water produced $(0.10 \mathrm{kWh} / \mathrm{k} \ell)$ and, therefore, presents the worst-case scenario for the eThekwini Municipality.

The units associated with the production and destruction of ozone consume about $4300 \mathrm{kWh} / \mathrm{d}$. The electricity consumption in the distribution and collection of water/wastewater is due to the pumping requirements of this system and amounts to $5200 \mathrm{kWh} / \mathrm{d}$ for distribution and $5600 \mathrm{kWh} / \mathrm{d}$ for collection. The activated sludge process consumes about $9700 \mathrm{kWh} / \mathrm{d}$. These processes have been examined in greater detail in order to see whether their consumption of electricity could be decreased in order to improve the overall environmental performance.

\section{Treatment of raw water and ozonation}

The ozonation unit at Wiggins Waterworks comprises 2 sections, namely the ozone generator, which uses electricity to generate ozone from oxygen, and the thermal destruction unit, which destroys the excess ozone by heating the gases to $300^{\circ} \mathrm{C}$. Of the $4300 \mathrm{kWh} / \mathrm{d}$ used by the ozonation unit, $3140 \mathrm{kWh} / \mathrm{d}$ $(72 \%)$ is used for the thermal destruction unit.

It was found that by limiting the air flow to the thermal destructor, thus increasing the concentration of ozone in the gas entering the unit and decreasing the total volumetric flow, the electricity consumption of the unit was decreased. A series of preliminary tests were run on the ozonators to determine the effect of reducing the gas flow to the thermal destruction unit by partially closing the vacuum breaker on top of the contactors. Also better control of the ozone dosing would reduce the need to have ozone destruction.

Based on trials that were conducted on this unit it was found that a $70 \%$ electricity reduction could be achieved. This would translate to a similar environmental saving. This is only one particular case study and this does not mean that similar savings could be achieved on all ozonation units; however, in this case it brought about large environmental savings which were achieved even during the course of the project.

\section{Collection and distribution of water and wastewater}

The improvement analysis for ozonation is based on technical improvements; however, when considering the distribution of potable water and the collection of wastewater more holistic approaches are needed. These approaches are classified into two broad categories: reducing consumer demand and reducing supplier demand. Supplier demand can be influenced by: identifying and reducing leakages in the reticulation networks, by removing illegal connections, by reducing excess pressure in the distribution system and by using economic instruments such as water tariffs. Consumer demand can be influenced by installing water saving devices (e.g. low-flow showerheads and toilets) and by local by-laws (e.g. water restrictions - prohibiting the use of potable water for garden watering).

\section{Reducing supplier demand}

At present approximately $30 \%$ of the amount of water purchased annually by the eThekwini Municipality from Umgeni Water is lost. This is due to illegal connections, metering inaccuracies and different types of leaks (main pipes, reservoir and service connection leaks). Because of this relatively high loss of water, a Non-Revenue Water (NRW) Branch has been established to reduce the amount of water lost in the distribution system.

Consumers with illegal connections will be incorporated into the billing system of the municipality. This will not reduce the total water demand; however, according the eThekwini Municipality's Integrated Development Plan (IDP) of 2005 there is a 5-year goal of reducing the number of illegal connections by $60 \%$. By 2008 substantial progress had been achieved in this regard.

Some of the measures introduced and ongoing are:

- Active leakage control. In the period from July 2006 to June 2007 a total length of $18300 \mathrm{~km}$ of main pipes have been checked and 30800 leaks have been identified and repaired. This process is ongoing.

- Better pressure control in the distribution system to avoid overpressure. This includes the installation of pressure-reducing valves in the different zones of the network, maintenance of these valves and the installation of warning devices on critical and strategic pressure-reducing valves. In addition advanced pressure control, a method which allows one 
to have 'normal' pressure during peak times and to reduce pressure out of peak times, has been rolled out in some areas of the distribution network.

- Measures targeting consumers include checking the top 1000 consumers in the system on an annual basis (includes replacing the water meters), installation of meters to previously unmetered consumers, the check-up of unmetered standpipes, visiting disconnected customers (convicted of non-payment or tampering) and removal of illegal connections, forced repairs for customers with arrears of over $60 \mathrm{~d}$ and where water consumption is greater than $1.5 \mathrm{k} \ell / \mathrm{d}$.

- Other general measures include reservoir zoning, modelling trunk reticulation systems, installation and maintenance of reservoir meters and real-time monitoring of reservoirs (still experimental).

Currently (2008) the target of the eThekwini Municipality is to reduce the loss in the distribution network from $30 \%$ to $20 \%$ by 2012 (Scruton, 2007). For large reticulation networks approximately $10 \%$ of water is lost through leaks which cannot be economically repaired (Bailey, 2003). A Swedish project investigating the environmental sustainability of urban systems stated that for a well-functioning network a $15 \%$ leakage rate was acceptable (Lundin, 1999). If the eThekwini Municipality measures are successful and a $20 \%$ loss is achieved, an additional $82 \mathrm{M \ell} / \mathrm{d}$ of water could be saved and the environmental burdens associated with the abstraction, treatment and distribution could be avoided. As an example, for the environmental impact category of global warming, achieving the $20 \%$ target water loss translates into $19600 \mathrm{~kg} \mathrm{CO}$ equivalents being saved per day. Achieving the best practice target of $10 \%$ loss would save $29400 \mathrm{~kg} \mathrm{CO}_{2}$ equivalents per day from being emitted (see Fig. 8).

\section{Reducing consumer demand}

Another way of increasing the available supply of water is to reduce the demand. Least-cost planning (LCP) has emerged as the way forward for water utilities in regions where water conservation has become an objective or where ongoing supply expansion is constrained (Fane, 2005).

Bailey (2003), in his study on domestic demand elasticity in the eThekwini Municipality, found that using water supply tariffs as a water management tool was one of the easiest ways of reducing consumer demand. This was also reported internationally (GWI/OECD Water Tariff Survey, 2007). In the eThekwini Municipality, the introduction of a new domestic tariff structure which would reward the use of less water and penalise heavy users of water (rising block tariff) would bring about substantial water savings, while protecting vulnerable groups and ensuring a balanced water revenue account. Using Ramsey pricing principles a pro-poor tariff structure was designed for the municipality. This tariff structure ensures that the poor have access to affordable water services while the high-income groups pay a premium to cross- subsidise the consumption of the lower groups. In keeping with the national government policy, the first $6 \mathrm{k} \ell / \mathrm{month}$ of water is free to all households. Bailey (2003) showed that by using this tariff structure an average reduction of $3.3 \%$ in consumer demand could be achieved. This is due to reductions in consumption from not only the high users of water, but all users. Lower income users reduce their demand in order to stay below the $6 \mathrm{k \ell} /$ month limit and thus do not pay for water at all, while middle- and high-income users reduce their demand to avoid being heavily penalised for using more than $30 \mathrm{k} \ell /$ month. The eThekwini Municipality currently supplies $820 \mathrm{M} \ell / \mathrm{d}$. A 3.3\%

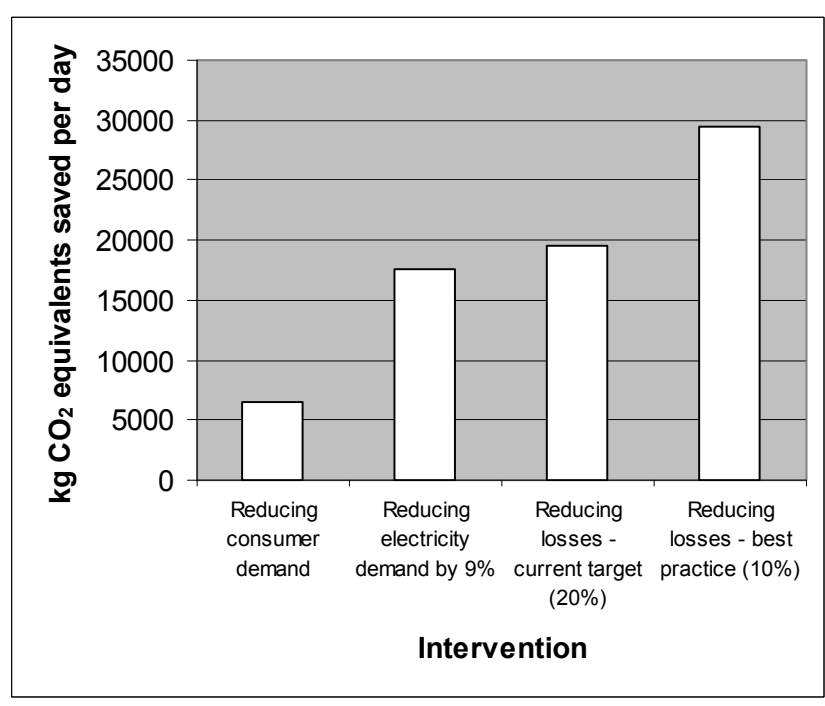

Figure 8

Environmental savings due to reducing consumer and supplier demand

reduction in demand would translate into almost $27 \mathrm{M} \ell$ water per day being saved and this translates into savings of 6450 $\mathrm{kg} \mathrm{CO}$ equivalents per day. Figure 8 summarises the savings due to reducing supplier and consumer demand for the impact category of global warming in order to illustrate some of the consequences of these interventions.

Another benefit of demand management is a reduction in electrical use. Lundie and Peters (2002) found that by using demand management the energy requirement for a system could be reduced by $4 \%$. Coupling this with energy-efficiency measures could reduce the electricity demand by a further $9 \%$. For this case study the $9 \%$ electricity savings translates into 17564 $\mathrm{kg} \mathrm{CO}$ equivalents per day (see Fig. 8).

In addition to the technical and managerial aspects presented above there is a whole array of social issues which have a bearing on the efficiency of the distribution and collection of water/ wastewater. Some of them, such as environmental education on the efficient use of water, have been and are employed by the eThekwini Municipality, other more innovative interventions still have to be explored. These, however, are not the focus of this paper but they would translate into environmental savings.

\section{Treatment of wastewater and the activated sludge process}

The impacts from the activated sludge units can be attributed to the large amount of electricity used for aeration. Surface aerators are used at the Southern Wastewater Treatment Works. Four possible ways of reducing the electrical load were investigated:

The $1^{\text {st }}$ one was to use process modelling to reduce overall energy consumption. This can be achieved by optimising parameters such as sludge age, wastage rate, aeration levels and recycle rates. A computer model was set up using the WEST (Worldwide Engine for Simulation, Training and Automation) software package to investigate these parameters. This process is on-going and quantification of possible improvements is not currently possible.

The $2^{\text {nd }}$ option which requires further investigation is the pretreatment of the influent to divert more solids to anaerobic digestion. Mels et al. (1999) showed that by introducing a chemically enhanced solids-removal step the energy requirements 
of the activated sludge process could be dramatically reduced. Coagulants and flocculants were added to the influent, followed by a sedimentation and/or flotation step. It was found that the electricity consumption could be reduced from $3100 \mathrm{MWh} / \mathrm{yr}$ to $50 \mathrm{MWh} / \mathrm{yr}$ for the sedimentation scenario and to $300 \mathrm{MWh} / \mathrm{yr}$ for the flotation scenario. For a South African treatment system this option is not used, as the cost of chemicals outweighs the electrical savings. However, the environmental improvements are potentially significant.

The $3^{\text {rd }}$ option involves the promotion of anaerobic digestion for high-strength liquid effluents and the use of the resulting methane to produce electricity. This electricity is used on the plant, reducing the need for grid energy. This strategy is promoted in Europe and the UK (DEFRA, 2007) and previous local studies (Sacks and Buckley, 2004) have shown that there is potential for such a process at the Southern Wastewater Treatment Plant. The anaerobic digesters on this plant have been decommissioned due to the disposal of sludge to sea for cost savings considerations. They have the capacity to take up to $13 \mathrm{t}$ $\mathrm{COD} / \mathrm{d}$ of high-strength biodegradable liquid effluent. In the light of new information and the drive to produce energy which might be linked to carbon credits, this decision should be reversed and the anaerobic digesters could be re-commissioned.

Finally, an aggressive industrial effluent waste minimisation campaign can be initiated in order to reduce the mass of COD being disposed to the wastewater treatment works. In addition, the introduction of a wastewater treatment tariff which more accurately reflects the cost of treatment, thus limiting the discharge of refractory and inhibitory substances to sewer should be encouraged. Background research on both these approaches has been initiated.

In summary, there is a high potential of environmental improvement for the system investigated. Some of these improvements are technological in nature and are straightforward to apply (e.g. increasing the efficiency of the thermal destruction units of the ozonators). Others are more complex in nature and require a combination of factors (technology, economics, social, etc.) for the optimal outcome. In this complex system LCA proves to be a good focusing tool, highlighting the areas with the highest environmental burdens, which have to be targeted for improvement. It can also be used to measure these improvements and provide a feedback on their efficiency.

\section{Conclusions and recommendations}

In this study it has been shown that a holistic system approach is needed for the assessment of the environmental performance in the provision of water and wastewater services. However, currently in the literature the process approach dominates. A process approach is valuable in prioritising improvements for a particular process and to enforce desired changes because different organisations/agencies are in charge of the different processes. However, it gives limited information on the overall performance of water systems. In this study a process comparison of the environmental scores due to the production of potable water and due to recycling wastewater for industry indicates there is a marginal benefit of recycling water. When the entire system is evaluated, the benefits are much greater. Most notably, the losses which are inherent to urban water systems, and are shown to be important, are included in a system approach and left out in a process approach. This study has shown how both approaches have to be combined to prioritise actions for environmental improvement and to achieve the desired changes.
From the LCAs of individual processes involved in the provision of water and wastewater in the eThekwini Municipality, it emerged that the process with the highest contribution is the activated sludge process - used in the treatment of wastewater. However, when considering the entire system and including the losses in the distribution network for potable water, the process with the highest contribution became the distribution network itself. This suggests that distribution should be prioritised for improvement as the benefits increase further down the system.

This study shows that energy consumption and the losses in the urban water systems are the most important factors contributing to the environmental burdens due to these systems. The conclusion with regard to the importance of energy is also supported by international studies. Reducing the losses is important, not only because of the savings associated with the treatment and distribution of water, but in a water-stressed country and in a catchment where demand is projected to outstrip supply, water is a resource which no longer can be wasted. Therefore, quantification of losses and active measures to reduce them is a priority action in order to increase the environmental performance of urban water systems in South Africa. Energy- efficiency studies need to be undertaken. As the improvement analysis showed, there are different options to address these 2 priority areas and each option or combinations thereof have different outcomes. It has to be underlined that energy efficiency is directly linked to the pumping requirements of the system and in turn these requirements are determined by the local conditions in which distances and elevations play an important role. Therefore, energy assessments of urban water systems can not be generalised and efficiency of systems/processes has to be researched in a case-by-case approach.

In the case study presented, recycling has positive environmental consequences and the replacement of virgin water with recycled water leads to high environmental savings and helps with the conservation of a vital resource. However, in the assessment of the environmental performance of recycling, an individual approach is needed since the environmental benefits can sometimes be smaller than the environmental burdens of the recycling process and the transport of the recycled water. In general, in South Africa, recycling operations should be encouraged if there is demand for industrial-grade water in the vicinity of wastewater treatment plants. This process will be even more efficient in inland locations because the standards for discharge are higher for rivers than the sea and only a small improvement in the quality of the discharged water will bring it to industry standards. Recycling will become environmentally inefficient if the quality of the wastewater is very low, the quality of the recycled water is required to be very high and if significant pumping and energy are needed to transport the recycled water to customers.

The value of environmental LCAs for urban water systems has been shown and its importance is demonstrated by focusing on improvements in complex systems and in measuring actual performance and the implication of changes. Therefore, LCAs with different degrees of sophistication (life-cycle thinking as well as simple and detailed LCAs) should be used to examine the consequences of all strategies, designs, interventions and changes to urban water and wastewater services. In general, the recommendations for long-term planning include the design of systems to enable more widespread, environmentally efficient water recycling. In the short term the main recommendations are the reduction of water losses and the reduction of energy consumption for urban water systems. 


\section{Acknowledgements}

The authors wish to express their gratitude for supporting this research to the following organisations:

Water Research Commission of South Africa, Umgeni Water, eThekwini Municipality, Durban Water Recycling, National Research Foundation of South Africa and University of KwaZulu-Natal Research Fund. In addition the contribution of the 3 anonymous reviewers is greatly appreciated.

\section{References}

BAILEY R (2003) Designing a Welfare Maximising Water Tariff for Durban with Ramsey Pricing Principles. MBA Dissertation, School of Business, University of Natal, Pietermaritzburg, South Africa.

BRIDLE T and SKRYPSKI-MANTELE S (2000) Assessment of sludge reuse options: A life cycle approach. Water Sci. Technol. 41 (8) 131135.

DEFRA - Department for Environment, Food and Rural Affairs (2007) UK Biomass Strategy 2007 Working paper 3: Anaerobic Digestion http://www.defra.gov.uk/Environment/climatechange/uk/energy/ renewablefuel/ (Accessed in Dec 2007).

DENNISON FJ, AZAPAGIC A, CLIFFT R and COLBOURNE JS (1998) Assessing management options for wastewater treatment works in the context of life cycle assessment. Water Sci.Technol. 38 (11) 23-30.

DWAF - Department of Water Affairs and Forestry (2004) Proposal to Establish the Mvoti to Mzimkulu Catchment Agency, Final Revised Version http://www.dwaf.gov.za/Documents/Other/CMA/Mvoti/ PD Mvoti RevisedFinal062004.doc (Accessed in Nov 2007).

DWAF - Department of Water Affairs and Forestry (2007) Development of a Water Reconciliation Strategy Study for the KwaZulu-Natal Coastal Metropolitan Areas http://www.dwaf.gov.za/Projects/ KZNWaterRecon/documents/KZNWaterReconBIDJun07.pdf (Accessed in Nov 2007).

EMMERSON RHC, MORSE GK, LESTER JN and EDGE DR (1995) The life-cycle analysis of small scale sewage-treatment processes. $J$ CIWEM 9 317-325.

ESKOM (2006) Environmental Report http://www.eskom.co.za/annreport06/tables2.htm (Accessed in Jan 2008).

ETHEKWINI GREENHOUSE GAS INVENTORY (2006) ftp://ftp. durban.gov.za/Engenv (Accessed in Sept 2007).

FANE AS (2005) Planning for Sustainable Urban Water: System Approaches and Distributed Strategies. Ph.D. Thesis, Institute for Sustainable Futures, University of Technology, Sydney, Australia

FRIEDRICH E (2001) The Use of Environmental Life Cycle Assessment for the Production of Potable Water. M.Sc. Eng. Thesis, Pollution Research Group, University of KwaZulu-Natal, Durban, South Africa.

FRIEDRICH E, BUCKLEY CA, PILLAY S and LESKE A (2006) A Life Cycle Assessment of a Secondary Water Supply. WRC Report No. 1252/1/06. Water Research Commission, Pretoria, South Africa.

FRIEDRICH E, BUCKLEY CA and PILLAY S (2007) The use of LCA in the water industry and the case for an environmental performance indicator. Water SA 33 (4) 443-451. http://www.wrc.org.za/ downloads/watersa/2007/Jul\%2007/2099.pdf

GUINEE JB, GOREE M, HEIJUNGS R, HUPPES G, KøEIJN R, DE KONING A, VAN OERS L, SLEESWIJK AW, SUH S, DE HAES HAV, DE BRUIJN H, VAN DUIN R and HUIJBREGTS MAJ (2001) Life Cycle Assessment - An Operational Guide to the ISO Standards. Center for Environmental Studies (CML), Leiden University, The Netherlands.
GWI/OECD Water Tariff Survey (2007) Tariff rises begin to hit home. Global Water Intelligence 8 (9) 31-34. Also available at http://www. globalwaterintel.com (Accessed in Dec 2007).

HWANG Y and HANAKI K (2000) The generation of $\mathrm{CO}_{2}$ in sewage sludge treatment systems: life cycle assessment. Water Sci. Technol. 14 (8) 107-113.

IDP (2005) Integrated Development Plan for the eThekwini Municipality available at: http://www.durban.gov.za/durban/government/ munadmin/policy/idp (Accessed in Nov 2007).

ISO 14040 (2006) Environmental Management - Life Cycle Assessment - Principles and Framework. International Organisation for Standardisation, Geneva, Switzerland.

LANDU L and BRENT AC (2006) Environmental life cycle assessment of water supply in South Africa: the Rosslyn industrial area as a case study. Water SA 32 (2) 249-256. http://www.wrc.org.za/downloads/ watersa/2006/April\%2006/1929.pdf

LESKE A and BUCKLEY CA (2004) Towards the development of a salinity impact category for South African life cycle assessments: Part 2 - A conceptual multimedia environmental fate and effect model. Water SA 30 (2) 241-252.

http://www.wrc.org.za/archives/watersa\%20archive/2004/Apr-04/11a. $\mathrm{pdf}$

LUNDIE S and PETERS G (2002) Sydney Water - WaterPlan 21 Life Cycle Assessment. Paper for the $3^{\text {rd }}$ Australian LCA Conference. 17-19 July 2002 Gold Coast, Australia.

http://ca-conf.alcas.asn.au/Papers/Lundie_Peters_Beavis_WP21.pdf (Accessed in June 2006).

LUNDIN M (1999) Assessment of the Environmental Sustainability of Urban Water Systems. Dept of Technical Environmental Planning, Chalmers University, Göteborg, Sweden.

MEIJERS K, VERBERNE AJP and KOREMAN EA (1998) Levenscyclusanalyse van membraanfiltraatie. $\mathrm{H}_{2} \mathrm{O} 21$ 33-36

MELS AR, VAN NIEUWENHUIJZEN AF, VAN DER GRAAF JHJM, KLAPWWIJK B, DE KONING J, RULKENS WH (1999) Sustainability criteria as a tool in the development of new sewage treatment methods. Water Sci. Technol. 39 (5) 243-250.

PILLAY SD (2007) An Environmental Life Cycle Assessment in the Provision of Recycled Water in Durban. Ph.D. Thesis, University of KwaZulu-Natal, Durban, South Africa.

RALUY GR, SERRA L and UCHE J (2005) Life Cycle Assessment of Water Production Technologies - Part 1: Life Cycle Assessment of Different Commercial Desalination Technologies. Int. J. LCA 10 (4) 285-293.

RIHON AC, LASSAUX S and GERMAIN A (2002) Application of the LCA methodology to water management from the pumping station to the wastewater treatment plant. Proc. $10^{\text {th }}$ SETAC LCA Case Studies Symp. 2-4 Dec 2002, Barcelona, Spain.

SACKS J and BUCKLEY CA (2004) Anaerobic Digestion of High Strength or Toxic Organic Effluents in Available Digester Capacity. WRC Report No. 762/1/04. Water Research Commission, Pretoria, South Africa.

SCRUTON S (2007) Personal communication. eThekwini Municipality Water Services, Durban, South Africa.

STOKES J and HORWATH A (2006) Life cycle energy assessment of alternative water supply. Int. J. LCA 11 (5) 335-343.

TARANTINI M. and FERRI F (2001) LCA of drinking and wastewater treatment systems of Bologna City: Final results. Proc. $4^{\text {th }}$ IRCEW Conf. 27-30 Aug Fortalenza, Brazil.

THOMPSON P (2006) Personal communication Umgeni Water, Durban, South Africa.

ZHANG Z and WILSON F (2000) Life cycle assessment of a sewage treatment plant in South-East Asia. J. CIWEM. 14 51-56. 